\title{
LEY DEL BORDE COSTERO Y CUESTIÓN ÉTNICA EN CHILE: DEL DISCURSO A LA PRÁCTICA POLÍTICA ${ }^{1}$
}

\author{
Coastline legislation and ethnic issues in Chile: From discourse to political practice \\ Claudio Espinoza Araya*
}

\section{RESUMEN}

Este artículo pretende mostrar de qué manera el proceso que condujo a la promulgación de la Ley No 20.249, también conocida como Ley del Borde Costero o Ley Lafkenche, refleja un interesante caso de cómo desde lo local se logró etnizar un espacio político determinado, la legislación marítima, confirmando de este modo que los actores indígenas disputan, en términos reales o simbólicos, espacios que son cada vez más significados como propios. Para ello se analiza el proceso político ocurrido entre 1992 y 2008 en Tirúa, una pequeña comuna del centro sur chileno, donde el alcalde mapuche Adolfo Millabur, junto a sus compañeros dirigentes, logró encauzar su pensamiento político hacia una práctica política concreta.

Palabras clave: Mapuche, etnopolítica, municipio, legislación pesquera, etnografía.

${ }^{1}$ Este artículo forma parte de una investigación realizada en el marco del Proyecto Fondecyt de Iniciación $\mathrm{N}^{\circ} 11130002$ "Transformaciones políticas infracomunales: Etnografía de experiencias etnopolíticas".

* Escuela de Antropología, Universidad Academia de Humanismo Cristiano. Santiago, Chile. I Investigador Asociado del Centro Interdisciplinario de Estudios Interculturales e Indígenas-ICIIS. Santiago, Chile. Proyecto: Conicyt/Fondap/15110006. Correo electrónico: cespinoza@academia.cl

Artículo recibido el 19 de noviembre de 2014. Aceptado el 01 de julio de 2015. 


\begin{abstract}
This article seeks to show how the leading process to the enactment of Law No. 20.249 Act, also known as Act Seaboard or Lafkenche Act, reflects an interesting case in which through the local space was possible to translate into an ethnic code the logics of a particular political space, the maritime legislation. This case confirms that the indigenous actors contests institutional spaces, in symbolic or objective terms, spaces that are increasingly ethnic meanings for this communities. This paper describes the political process happened from 1992 to 2008 in Tirúa, a small town in south central Chile where Mapuche mayor Adolfo Millabur, with his fellow leaders, was success to put his political thinking in movement in a particular way of local political practice.
\end{abstract}

Keywords: Mapuche, ethnopolitics, municipality, fisheries legislation, ethnography.

\title{
INTRODUCCIÓN
}

A partir de 1992, ańo de las primeras elecciones municipales post dictadura, Tirúa ${ }^{2}$ vivió un extraordinario período de transformaciones políticas. El dato más revelador de aquello guarda relación con la evolución observada en la distribución del poder político municipal, donde los mapuches, actores mayormente excluidos del sistema político electoral chileno, fueron aumentando su presencia entre las autoridades municipales hasta al punto de hacerla casi absoluta.

En términos concretos, el concejo municipal de Tirúa, compuesto hasta las elecciones de 2004 por seis personas, un alcalde y cinco concejales, y después de 2004 por un concejal más, pasó de estar integrado en 1992 por cinco autoridades no indígenas y una sola indígena, a estar constituido desde 2008, y hasta la fecha, por seis autoridades mapuches y solo una no indígena. Escenario diametralmente opuesto (Ver gráfico 1).

Esto pudo ocurrir porque durante este período se desarrolló en Tirúa un movimiento etnopolítico que dio por resultado un empoderamiento de las comunidades mapuches agrupadas en territorios infracomunales, con la consecuente

\footnotetext{
${ }^{2}$ Tirúa es una comuna del centro sur chileno creada por decreto presidencial en 1972. Ubicada en la zona más austral de la Provincia de Arauco, en la Región del Biobío, posee una población que bordea los 10.000 habitantes, divididos en porcentajes cercanos entre personas que se autoreconocen como mapuches y quienes lo hacen como no indígenas (47\% y 53\%, respectivamente según censo 2002). Desde 1992 la comuna se vio inmersa en un interesante proceso político, que tuvo en la gestión y figura del alcalde Millabur una de sus principales expresiones. Adolfo Millabur fue electo concejal en 1992, en 1996 se convirtió en el primer alcalde indígena de la comuna, cargo en el cual se mantuvo por tres períodos consecutivos. En las elecciones de 2008 fue derrotado por escaso margen por otro alcalde mapuche, José Aniñir. En 2012 volvió a ser electo alcalde de la comuna.
} 
reconfiguración del territorio comunal; una apertura del campo político hacia otros lugares, tiempos y actores; una emergencia de nuevos liderazgos indígenas y una competencia por el poder municipal, todos elementos que contribuyeron a modificar de manera sustancial la distribución del poder político de la comuna (Espinoza, 2011).

\section{Gráfico 1}

Adscripción étnica autoridades municipales de Tirúa

Período 1972-2016

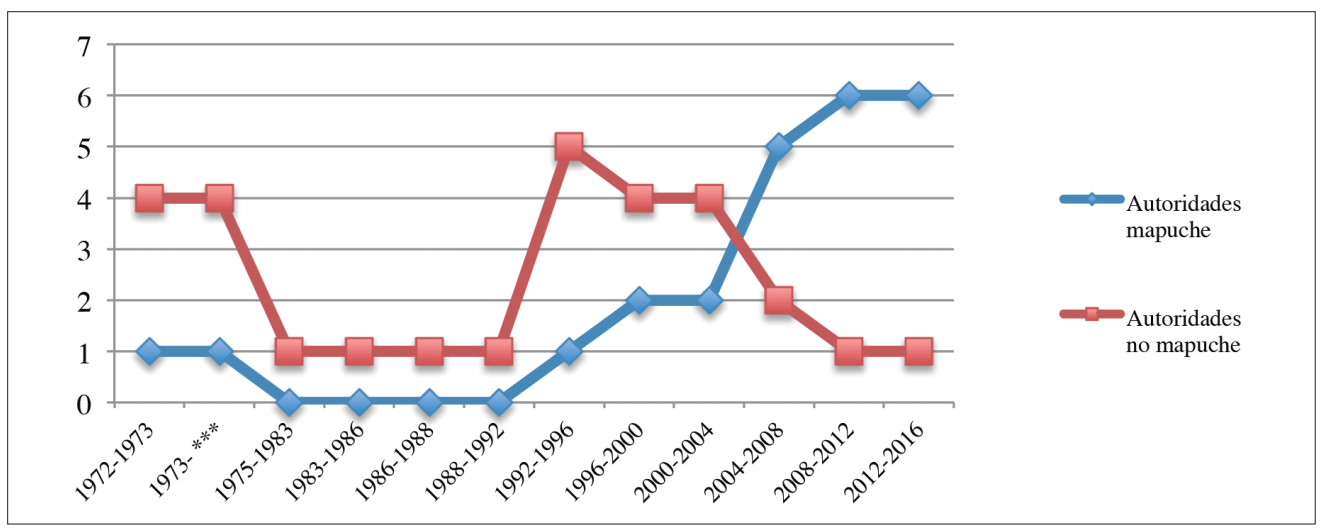

Elaboración propia con datos del servicio electoral chileno (www.servel.cl)

Este movimiento etnopolítico fue dirigido por jóvenes mapuches que representaron a cabalidad las nuevas orientaciones que adquirió el movimiento mapuche contemporáneo, post década de 1980, es decir un movimiento fuertemente étnico (Bengoa, 1999; Mella, 2001) o, al menos, más fuerte de lo que había sido durante los ańos anteriores (Pinto, 2012). Dicho movimiento se encontró con cambios estructurales relacionados con los procesos de reforma del Estado y con una coyuntura específica: la transición democrática chilena. Este contexto fue aprovechado por los dirigentes mapuches para, de manera paulatina, poner en práctica una ideología política desde el control municipal.

Esta práctica política coincidió con el nuevo sitial ocupado por los gobiernos locales en América Latina (Assies, 2003; Dehouve, 2001; Espinosa, 2003; Delamaza, 2005), donde muchos colectivos indígenas, a través de la vía electoral (Iturralde, 1998; Ramírez, 2009; Albó, 2012), se volcaron hacia su control. Este control se hizo en muchos casos a través de movimientos etnopolíticos (Bartolomé, 1997; De la Peña, 1999; Zárate, 1994; Le Bot, 2013) que intentaron la etnización del espacio político municipal (Burguete, 2008; Harvey, 2008), es decir, mediante un proceso de reinvención y reafirmación de la identidad étnica que, en paralelo, ejerció acciones políticas activamente construidas para visibilizarse como indígenas 
y reclamar derechos o establecer políticas en función de dicho reconocimiento (Restrepo, 2001; Gros, 2003; Hoffmann y Rodríguez, 2007). En el fondo se observó el anhelo por trascender el simple cambio formal en la distribución del poder político municipal para intentar que los gobiernos locales en manos indígenas tuvieran un sello propio (Laurent, 2005; Ospina, 2006; Ramírez, 2007).

A pesar de que el proceso político ocurrido en Tirúa llevó fuertemente el sello de lo local, no permaneció impermeable a las fuerzas regionales, nacionales y globales que lo envuelven. Por el contrario, dicho proceso fue influido, explícita e implícitamente, por fuerzas políticas y económicas mayores, por ejemplo, la dinámica de los partidos políticos o las agencias financiadoras internacionales. Pero también, y hay que decirlo, estas fuerzas mayores fueron afectadas por el proceso político local.

Ahora bien, dentro del abanico de arenas políticas posible de observar en el proceso de etnización de la política municipal, apareció con fuerza el camino que condujo a la promulgación en 2008 de la Ley 20.249, también conocida como Ley del Borde Costero o Ley Lafkenche. Se trató de un largo proceso, en el que durante 16 años, con distinta intensidad y extensión, hubo una organización de comunidades mapuches lafkenches que trabajó para hacer posible la promulgación de dicha Ley, cuestión que fue percibida posteriormente como un gran logro por tales comunidades. Y si bien se trató finalmente de un amplio movimiento que incluyó a comunidades indígenas costeras de cuatro regiones del sur del país ${ }^{3}$, lo cierto es que el centro neurálgico del movimiento quedó instaurado en la comuna de Tirúa y tuvo en el alcalde Millabur a uno, sino el más destacado, de sus líderes. De ahí la importancia de analizar el movimiento conducente a la Ley del Borde Costero en relación con las transformaciones políticas ocurridas en el espacio local de Tirúa. Por ello se comenzará describiendo someramente parte del pensamiento político de los líderes mapuche que encabezaron el proceso, para luego ver cómo dichos discursos se volvieron práctica política. Finalmente se describirá parte de la evolución que tuvo el trabajo en torno a la confección de la Ley, su articulación a algunas de las transformaciones que ocurrieron en el nivel local y, por último, qué tipo de cuestiones se pusieron en juego y pueden ser extraídas para el análisis sociocultural.

\section{LA BASE IDEOLÓGICA DE UN PROYECTO ETNOPOLÍTICO}

Una buena entrada para analizar el pensamiento político de los líderes mapuche de Tirúa es hacer uso de un planteamiento relativamente compartido respecto a determinadas características que poseería el movimiento mapuche contemporáneo. Esta heterogénea base organizacional ha sido analizada por autores

\footnotetext{
${ }^{3}$ En concreto las regiones son: Región del Biobío, de La Araucanía, de Los Ríos y de Los Lagos.
} 
como Foerster y Vergara (2002) quienes, entre otros aspectos, han señalado cierto número de limitaciones que la definirían. Con la intención de comprender algunas de las condiciones que ayudan a gestar el proceso que derivó en la Ley del Borde Costero, en esta argumentación se recurrirá a tres de estas limitaciones.

En primer lugar, los autores observan una atomización o segmentación del movimiento mapuche en múltiples organizaciones, donde cada una se consideraría a sí misma como la genuina representante del pueblo mapuche. El movimiento, por lo tanto, permanecería constantemente dividido. En segundo lugar, destacan el hecho de que en los últimos años el movimiento mapuche no habría logrado incorporar en sus luchas a amplios sectores de la sociedad mapuche, impidiendo con ello ampliar la base social del movimiento. Por último, afirman que el movimiento se ha mostrado débil en cuanto a su capacidad para modificar los términos en que el Estado chileno ha definido las relaciones con los pueblos indígenas, no logrando, por tanto, la consecución de metas concretas para las aspiraciones indígenas (Foerster y Vergara, 2002) ${ }^{4}$.

A partir de distintas entrevistas concedidas por el alcalde Adolfo Millabur (Pangea.org, 2000; Foerster y Vergara, 2001; Cattaneo, 2004; Espinoza, 2011), es posible constatar en su visión una estrecha relación con el diagnóstico de los autores antes mencionados. Para empezar, el alcalde recalca la necesidad de fundar una organización basada en la territorialidad mapuche, lo cual otorgaría una mayor sintonía con la sensibilidad local y con ello una mayor incorporación de personas. Después, señala la importancia de instaurar una organización que no pretenda ser la representante de todo el pueblo mapuche, sino que se ciña a espacios más delimitados -tal vez más homogéneos-, como las identidades territoriales, en su caso la Identidad Lafkenche. En este sentido, la escuela política de los dirigentes mapuches liderados por Millabur buscó una reinvención/recomposición de las identidades territoriales mapuches. En el discurso del alcalde, además, se lee con claridad la necesidad de aprovechar las estructuras del Estado para reposicionar las demandas mapuches y, a la vez, que permitan la consecución de logros para el mundo indígena:

Nosotros no nos queremos organizar en asociaciones gremiales o coordinadoras, nosotros queremos reconocimiento como tal, como lafkenche. Nosotros no nos hemos declarado nunca dirigentes nacionales. Las otras organizaciones nacionales están en crisis porque no se han basado en la territorialidad. Hasta hoy, no ha habido ninguna organización de nivel nacional eficiente, ellas abarcan mucho y aprietan poco... (Adolfo Millabur, citado en Cattaneo, 2004).

\footnotetext{
${ }^{4}$ Este diagnóstico publicado en 2002, ha sido reafirmado en una publicación más reciente. Véase Vergara, Gundermann y Foerster, 2013.
} 
Las municipalidades tienen un poder enorme en cuanto a lo que es la actividad local, [...] creo que las municipalidades son importantes de controlar, para poder crear una especie de sintonía con la aspiración del pueblo mapuche con lo que tiene que hacer un municipio a nivel local, [...] Yo siempre he estado en el esfuerzo de poder estar en sintonía en lo que plantean las comunidades mapuches, como aspiración de pueblo, más allá de las aspiraciones de orden asistencial. Y esa es nuestra apuesta, tratando de aprovechar la estructura del Estado, con la característica que los alcaldes tienen autonomía frente al resto de los poderes del Estado. Yo creo que ser gobernador no es lo mismo que ser alcalde; ser un intendente no sirve mucho en el sentido que es subalterno de un presidente. El alcalde no es subalterno de un presidente, por lo tanto tiene la libertad de plantear, decidir, generar, reivindicar las cosas que le parecen legítimas. Y nosotros a partir del cargo de la alcaldía hemos tratado de hacer eso (Adolfo Millabur, citado en Foerster y Lavanchy, 1999).

Pues bien, estas y otras ideas se volvieron carne en un lugar concreto y en una época precisa. A fines de la década de 1980 un grupo de jóvenes mapuches que egresaban de la educación escolar en Tirúa, dejaron la comuna y se fueron a estudiar a la cercana ciudad de Concepción. Allí, en el hogar mapuche Pegun Dugun ${ }^{5}$, se formaron como técnicos y profesionales, pero sobre todo como dirigentes. A principio de la década de 1990, estos jóvenes dirigentes, entre los que se contaba a Adolfo Millabur, Iván Carilao, José Linco y José Huenchunao ${ }^{6}$-más tarde entró en escena Evangelina Faúndez-, regresaron a Tirúa decididos a iniciar, o continuar de manera más intensa, un proceso a través del cual pudieran dar curso a las ideas políticas que habían sido afinadas en los años de Pegun Dugun.

En ese primer momento estos jóvenes dirigentes no dan muestra de tener completa claridad respecto de la vía por donde encauzar la lucha política. En un comienzo, podría decirse, la arena política no está suficientemente definida. Hay certeza eso sí, respecto a los actores involucrados, comunidades mapuches de Tirúa, por un lado, y el Estado por el otro, pero aún no disponen de una bandera de lucha distintiva, exclusiva, propia del nuevo movimiento que se estaba generando.

Su discurso inicial reproduce el discurso enarbolado por casi la totalidad de las organizaciones mapuches contemporáneas. Deuda histórica, devolución de las

\footnotetext{
${ }^{5}$ Los denominados Hogares mapuches, o casas de acogidas para estudiantes mapuches rurales que ingresan a la educación superior en las mayores ciudades del país (Santiago, Concepción y Temuco, entre las principales), nacen aproximadamente en la década de 1950 y en las últimas dos décadas han jugado un rol fundamental en la preparación de nuevo dirigentes, organizaciones, discursos y acciones mapuches (Flores y Robles, 2007).

${ }^{6}$ Durante los periodos alcaldicios de Millabur, tanto Iván Carilao, José Linco y Evangelina Faúndez, fueron parte integrante del equipo político del alcalde. José Huenchunao en cambio, a partir de 1996 se alejó del grupo por diferencias políticas y pasó a integrar la organización Coordinadora de Comunidades en Conflicto Arauco-Malleco, más conocida como CAM.
} 
tierras usurpadas, acceso a educación y salud, fueron algunos de los temas a los cuales los jóvenes dirigentes de Tirúa recurrieron durante sus primeras reuniones políticas en la comuna. Pero en 1991 ocurre algo que permite a estos dirigentes identificar una nueva ruta reivindicativa a seguir $\mathrm{y}$, aferrándose a ella, lograron constituir a lo largo de 16 años un amplio movimiento social que obtuvo importantes resultados para las comunidades del borde costero.

Evangelina Faúndez describe algunos de los hitos de este proceso:

En ese tiempo se comienza a trabajar con Arauco, Cañete y Tirúa, hasta ahí llegaba. Hasta ese entonces nosotros habíamos hablado de educación, salud, de la deuda histórica... porque esa es la primera propuesta que nosotros presentamos al gobierno [...] Al tiempo los viejos comienzan a preocuparse del borde costero, más o menos en 1992. Por ahí se promulga la Ley..., y entonces comienzan a trabajar como territorio y comienzan a unirse con Carahue. Entonces ya había una característica cultural que los unía [...] El tema de la identidad territorial comienza por el mar. Ese sería el tema que une a todas las comunidades que van desde Palena hasta Arauco [...] lo que nos une a los lafkenches es el tema del mar. El mar es el nexo cultural que nos une como comunidades lafkenches...(Evangelina Faúndez, citada en Espinoza, 2011).

$\mathrm{Al}$ aprobarse la Ley de Pesca y Acuicultura de 1991 que, a grandes rasgos, introdujo una serie de restricciones al uso y explotación del mar, por ejemplo limitando el libre acceso, obligando a una explotación controlada por parte de sindicatos de pescadores a los cuales les correspondería una determinada área de extracción, las llamadas áreas de manejo, poniendo con ello en tensión sistemas tradicionales de pesca con nuevos sistemas institucionalizados (Gelcich et al., 2006), las comunidades mapuches de Tirúa comenzaron a analizarla y ver las consecuencias que acarrearía respecto a su relación con el mar, pues un alto porcentaje de las comunidades de la comuna practican de forma regular la recolección de algas marinas y moluscos, actividad que constituye una de las principales fuentes de su reproducción económica. Allí hay, entonces, un primer elemento que convoca a las comunidades involucradas.

Los testimonios difieren en cuanto a quién fue el líder aglutinador. Algunos dirigentes señalan que es con Millabur con quien parte el proceso, otros dicen que este se suma cuando ya se había iniciado. Parece ser que esta segunda opinión es la que más se acerca a la realidad. Sea como sea, la presencia de Millabur es fundamental y, a la larga, la Ley del Borde Costero se convirtió en su principal caballito de batalla y en un gran logro que muchas personas no dudan en atribuir a su accionar, tanto en su rol como dirigente y como alcalde de Tirúa.

Ahora bien, la primera decisión de los dirigentes de las comunidades del centro y sur de Tirúa guardó escasa relación con el espíritu final que tuvo el proceso, es decir, 
con la formulación de una Ley que incorporó planteamientos étnico-culturales. Al principio se trató más bien de buscar una forma de integrarse a la Ley de 1991, de no quedar excluidos de la nueva normativa que regulaba la explotación marítima. Así, en un comienzo, las comunidades de Tirúa Sur, aglutinadas en la gran organización de la zona, la asociación Pu Lafkenche, obtuvieron un área de manejo, sin embargo, y aquí viene la influencia de Millabur, con el tiempo se leyó críticamente esta inclusión en los mecanismos y figuras de la Ley de 1991 y, con ello, se dio paso a una nueva etapa que a la postre derivaría en la propuesta de una nueva Ley con sello étnico.

Millabur, ya instalado como alcalde de Tirúa, desde 1996 en adelante, comenzó a promover encuentros entre comunidades costeras de manera cada vez más periódica. Pero ya no solo se trató de comunidades indígenas de Tirúa, sino que con el tiempo se fueron sumando mapuches lafkenches de otras comunas. Las primeras comunidades fuera de Tirúa en integrarse a estos encuentros, a estos tragünes, fueron las de la comuna de Carahue, ubicada inmediatamente al sur de Tirúa, en la vecina Región de la Araucanía.

De hecho fue este tipo de encuentros y temáticas los que estimularon el nacimiento de otra gran organización lafkenche, la asociación Newen Pu Lafkenche, cuya creación tuvo lugar en 1998 a partir de la conjunción de ocho comunidades pertenecientes al borde costero de Carahue ${ }^{7}$. Luego se fueron sumando más y más comunidades, hasta conformar un bloque que incluyó comunidades de cuatro regiones del sur del país.

Este tipo de reuniones fueron promovidas por la organización Identidad Territorial Lafkenche, de la cual Millabur es líder y fundador, y financiadas por recursos obtenidos tanto de ONGs extranjeras y nacionales, así como por el propio Estado chileno, a través de programas y financiamientos generados desde la Corporación Nacional de Desarrollo Indígena (CONADI). Se trataba de reuniones multitemáticas donde, por ejemplo, se realizaban talleres de fomento a la cultura mapuche, pero donde por sobre todo se discutía la Ley de Pesca. En el fondo eran grandes reuniones políticas donde la Identidad Territorial Lafkenche, y muy especialmente Millabur, desplegaba y difundía su contenido ideológico, con el objetivo de crear y estimular una conciencia política alineada a la filosofía política de este movimiento etnopolítico.

Estos encuentros se convirtieron en prácticas regulares. Desde el año 2000 los tragünes en Tirúa, sobre todo en Tirúa, pero también cada vez más fuera de las fronteras comunales y regionales, comenzaron a ser más frecuentes, y en ellos Millabur exponía

\footnotetext{
${ }^{7}$ Para más información respecto a esta organización véase Boccara, 2004. Por otra parte, hay que señalar, siguiendo a Susana Huenul (2012), que la articulación de las comunidades de Tirúa y Carahue ocurrió también a propósito de otros hechos y otros problemas, por ejemplo, la construcción de la Carretera de la Costa.
} 
con claridad y fuerza su pensamiento político. Por su parte, las comunidades mapuches se organizaban, intensificaban los lazos que ya tenían con las comunidades aledañas, con las que poseían alianzas rituales y de parentesco, y estrechaban lazos con comunidades más lejanas. También se presentaron conflictos, es cierto, hubo comunidades que se retiraron del proceso, pero la mayoría continuó y a medida que pasaron los años se fueron alineando a la órbita del alcalde Millabur y de la Identidad Territorial Lafkenche.

De estos encuentros fue naciendo ya no una demanda económica, como había sido la primera exigencia de los dirigentes de Tirúa Sur Costa -no quedar excluidos de la Ley de 1991-, sino una demanda étnico-cultural. Poco a poco los dirigentes llegaron a la conclusión de que la figura de las áreas de manejo no coincidía con sus aspiraciones, básicamente porque si bien en el caso de Pu Lafkenche la legislación había reconocido formalmente a una organización mapuche y no necesariamente a un sindicato de pescadores (aunque englobada bajo la misma categoría de sindicato), los dirigentes sospechaban que la Ley no reconocería otro tipo de estructura política mapuche, como por ejemplo la comunidad o a una asociación de ellas como administradoras de un sector marítimo. Además, la Ley establecía que después de cuatro años de uso de una determinada área de manejo había que comenzar a pagar impuestos y derechos por su uso y explotación. Las reflexiones y discusiones terminaron finalmente en un diagnóstico crítico hacia ella. La organización Identidad Territorial Lafkenche expresó con claridad sus reparos a la Ley de Pesca y Acuicultura de 1991, señalando, entre otros aspectos, que esta no reconocía las estructuras organizacionales ni la existencia de trabajadores del mar pertenecientes al mundo indígena, obligándolos a adoptar formas de organización ajenas a su cultura; que privaba a las comunidades el libre acceso al mar y a los recursos que ancestralmente han utilizado, impidiendo con ello la relación cotidiana de los mapuche-lafkenches con el mar, tanto en un sentido material como espiritual. Por último, esta legislación provocaba conflictos con asociaciones y sindicatos de pescadores artesanales ajenos a las comunidades.

Una vez explicitado este diagnóstico y tras el posicionamiento exitoso de la Identidad Territorial Lafkenche en las comunidades mapuches costeras del sur del país, se inició un proceso que buscó modificar la situación en la que quedaban las comunidades mapuche-lafkenches bajo el marco legal de 1991. Se pasó, una vez más, del discurso a la acción.

Como ha sido la tónica de este movimiento, o más bien de esta vía del movimiento mapuche ${ }^{9}$, lo primero fue buscar, mediante una negociación

\footnotetext{
${ }^{8}$ Véase en línea www.identidadlafkenche.cl. [Consultado el 20 de diciembre de 2011].

${ }^{9}$ Si bien el escenario político contemporáneo se ha mostrado desfavorable para las aspiraciones de los pueblos originarios, las organizaciones indígenas continúan desplegando nuevas formas de lucha y estrategias de resistencia, las cuales han cristalizado en movimientos sociales que expresan una alta
} 
permanente, soluciones dentro de la estructura institucional. Para ello los dirigentes mapuches sostuvieron reuniones con las autoridades nacionales, básicamente con ministros de Estado y en ocasiones con los presidentes de la República de cada momento, Lagos y Bachelet, principalmente. Después de algunos desencuentros ${ }^{10}$, en el año 2002 se estableció un compromiso entre la Identidad Territorial Lafkenche y el gobierno, donde la primera debía elaborar una propuesta respecto del uso del borde costero, y el segundo se comprometió a respaldar dicha propuesta mediante una iniciativa legal que reconociera el derecho de los mapuche-lafkenches sobre el mar y sus recursos.

De esta forma, a través de un proceso sumamente participativo y del transcurso de varios ańos en negociaciones con el ejecutivo, las comunidades mapuche lafkenches, apoyadas por equipos técnicos y políticos del Programa Servicio País y del Gobierno, elaboraron el Proyecto de Ley que crea el Espacio Costero de los Pueblos Originarios. Finalmente, el 20 de noviembre de 2007 se aprobó en el Congreso Nacional la Ley No 20.249, promulgada oficialmente en febrero de 2008.

Ahora bien, a partir de esta breve y acotada descripción del proceso político conducente a la Ley del Borde Costero, es posible extraer algunos ejes útiles para la reflexión que se intenta en este artículo.

\section{LA PUESTA EN PRÁCTICA DEL DISCURSO ÉTNICO}

Si bien la primera puesta en práctica del discurso político de Millabur se concretó en la arena electoral al momento de hacerse con la alcaldía de Tirúa, la elaboración de la Ley del Borde Costero constituyó otra gran puesta en práctica del discurso millaburista, en el sentido de que tanto en el proceso, la forma y el fondo, como en la meta alcanzada, se dejaron ver con toda claridad algunos de los principales planteamientos ideológicos del líder mapuche.

capacidad de actuar políticamente frente al Estado y los distintos gobiernos (Bello, 2008). En este contexto se han logrado identificar algunos tipos de estrategias indígenas. Burguete (2008), fijando su atención sobre todo en el caso mexicano, pero que, creemos, es extensible a otras realidades latinoamericanas, ha identificado tres tipos de estrategias indígenas: a) Dentro del Estado, b) Contra el Estado y, c) Fuera del Estado. El caso seguido en este artículo encuentra cierta identificación con la primera estrategia seńalada por la autora, es decir, una organización, la Identidad Territorial Lafkenche, que a través de la negociación constante disputa espacios de poder al Estado, pero sin salirse de la institucionalidad.

${ }^{10}$ La gente no olvida la ocasión en que se preparó un gran encuentro para recibir al presidente Lagos y este, a último momento decidió no asistir, generando molestia y decepción entre las personas que lo esperaban. 
Con base en el pensamiento político de Millabur, ya sea en sus críticas al movimiento mapuche contemporáneo como en sus propuestas concretas, una primera demostración de la puesta en práctica del discurso queda graficada en el hecho de que las acciones de Millabur, así como las de la Identidad Territorial Lafkenche, siempre se desenvolvieron dentro del ámbito de la institucionalidad, es decir, siempre tuvieron como interlocutor al Estado y a los órganos de gobierno. Como se señaló en una nota más arriba, se trata de una vía del movimiento mapuche que, sin salirse del marco institucional, le disputa poder al Estado. La primera y más evidente prueba de esto fue competir por la administración del poder local, pero también lo fue la idea de competir por la administración del territorio, en este caso el borde costero, dentro de la propia institucionalidad del Estado. En este sentido, se encarna la idea de aprovechar la estructura estatal para alcanzar metas concretas para el pueblo mapuche.

En segundo lugar, y en coherencia con el devenir de las demandas mapuches en las últimas décadas, se trata de un proceso y una ley que se insertan de lleno en el horizonte de lo étnico. La demanda en torno al borde costero, si bien tiene una base económica, como pudo observarse en las primeras propuestas de las comunidades costeras de Tirúa, en el fondo es una demanda étnica: una porción del territorio nacional con derechos diferenciados para una determinada población que se define a sí misma como étnica y culturalmente diferente al resto de la nación.

En tercer lugar, Millabur, en consonancia con el trabajo de los antropólogos Foerster y Vergara (2001), comparte la idea de que el movimiento mapuche contemporáneo se ha basado en muchas organizaciones, más bien débiles, cada una de las cuales se ha sentido la genuina representante del pueblo mapuche. Estas organizaciones, además, no habrían logrado incorporar a las bases mapuches sino que, en el fondo, se trataría de cúpulas que tanto en sus discursos como en sus acciones no han logrado involucrar las dinámicas y aspiraciones de las comunidades reales.

Por el contrario, el movimiento en torno a la Ley del Borde Costero provocó que de manera progresiva se fueran sumando cada vez más personas y comunidades mapuches. Se involucraron prácticamente la totalidad de las comunidades mapuches de Tirúa y muchas otras de comunas costeras del sur del país, lo que conformó finalmente una participación que comprometió a un extenso territorio. De este modo se contribuyó a generar un movimiento sumamente significativo en el amplio abanico de las demandas indígenas del Chile contemporáneo, ya no a partir de una autoproclamación como representantes de todo el pueblo mapuche, sino ceñido a una fracción, a un territorio, a una identidad territorial: la Identidad Lafkenche.

Millabur y los dirigentes mapuches de este movimiento cumplieron con su premisa de basar la organización de los mapuches en la noción de territorialidad. 
En este sentido la Ley de Pesca de 1991 les fue muy útil, puesto que permitió dar consistencia material a la idea de identidad territorial ¿Qué es lo que une a las comunidades mapuches de la costa? El mar. Tal cual lo sostiene Evangelina Faúndez, el mar es el nexo cultural que vincula a los mapuche-lafkenches. La oposición a la Ley de 1991 y el proceso de conformación del nuevo marco legal aprobado en 2008 se convirtieron en argumentos ideales para aglutinar a las comunidades costeras, para generar un discurso unitario, una bandera de lucha común a los mapuches de la costa, una materia concreta que dio unidad a la idea, reinventada o reconstruida, de identidad territorial lafkenche. Así, una ley nacional contribuyó a desatar procesos políticos y culturales diversos en el ámbito local.

Por último, y de manera relevante, la Ley del Borde Costero vino a constituir una puesta en práctica del discurso en cuanto tuvo un final exitoso. En contraste a otra de las críticas al movimiento mapuche que apuntaba al fracaso en cuanto a la no modificación de la relación entre el Estado y los pueblos indígenas, es decir, en la no consecución de logros significativos, el movimiento articulado a Millabur y a la Identidad Territorial Lafkenche obtuvo un resultado en extremo valioso: nada menos que una ley que garantiza la administración de un territorio marítimo a las comunidades que posean sobre él un uso consuetudinario.

\section{CONCLUSIONES}

Es posible plantear que el proceso conducente a la promulgación de la ley No 20.249 implicó una serie de elementos que permiten vislumbrar el complejo escenario contemporáneo que envuelve a los Estados, a los gobiernos y a los pueblos indígenas. Para empezar, se puede apreciar cómo ciertos procesos nacionales, en su mayoría concebidos e impuestos de manera unilateral, como por ejemplo, la Ley General de Pesca y Acuicultura, No 18.892 de 1991, pueden provocar, y de hecho lo hacen, reacciones disímiles, muchas veces no planificadas ni esperadas, en los escenarios locales. En este caso una ley de carácter nacional provocó todo un reacomodo político en el nivel local, posibilitando una reacción concreta a dicha medida legislativa.

Luego, el caso seguido en este artículo permite observar lo complejo y muchas veces contradictorio que puede llegar a ser el plano de las decisiones de los actores sociales. Como se vio, la primera reacción de los comuneros mapuches de Tirúa Sur fue el intento, logrado, de conseguir un área de manejo, sin embargo, unas de las distintas vertientes que se pudieron apreciar del proyecto etnopolítico de Millabur y compañía, fue el hecho de posibilitar la generación de una conciencia étnica que trascendiera el marco argumentativo de la Ley y pudiera replantearse la discusión desde otro lugar, desde la etnicidad y, además, conseguir el resultado 
esperado. En este sentido es importante constatar cómo desde lo local, a través de la negociación constante, se pudo impactar e influir en el nivel nacional, consiguiendo un logro inédito en la relación entre el Estado y los pueblos indígenas.

Finalmente, interesa subrayar que, englobado tanto en el proceso previo como en el logro alcanzado, el movimiento social generado en torno a la Ley del Borde Costero representa, también, un intento relativamente exitoso de resistencia a la política neoliberal y a las territorialidades impuestas por el Estado.

\section{REFERENCIAS}

Albó, Xavier. Tres municipios andinos camino a la autonomía indígena: Jesús de Machaca, Chayanta, Tarabuco. La Paz: Centro de Investigación y Promoción del Campesinado (CIPCA), 2012.

Assies, Willem. "La descentralización en perspectiva". En Willem Assies (Ed.), Gobiernos locales y reforma del Estado en América latina. Zamora: El Colegio de Michoacán (COLMICH), (2003): 13-34.

Bartolomé, Miguel. Gente de costumbre y gente de razón: Las identidades étnicas en México. México D.F: Siglo XXI Editores, 1997.

Bello, Álvaro. "Los pueblos indígenas y las contradicciones de la globalización". Globalización, derechos Humanos y pueblos indígenas. En Âlvaro Bello y José Aylwin (Comp.), Temuco: Observatorio de Derechos de los pueblos Indígenas, (2008): 48-65.

Bengoa, José. Historia de un conflicto. El Estado y los mapuches en el siglo XX. Santiago, Chile: Planeta, 1999.

Boccara, Guillaume. "Del Buen Gobierno en Territorio Mapuche. Notas acerca de una experiencia en salud complementaria", Cuadernos de Antropología Social 20 (2004): 113-129.

Burguete, Aracely. "Gobernar en la diversidad en tiempos de multiculturalismo en América Latina”. Gobernar (en) la diversidad: Experiencias indígenas desde América Latina. Hacia la investigación de co-labor. En Xochitl Leyva, Araceli Burguete y Shannon Speed (coords.), México, D.F: Centro de Investigaciones y Estudios Superiores en Antropología Social (CIESAS), Facultad Latinoamerica de Ciencias Sociales (FLACSO) Ecuador y Guatemala (2008): 15- 64. 
Cattaneo, Rodrigo. "Dynamiques organisationnelles et stratégies territoriales des groupes résidentiels mapuche-lafkenche de la commune de Tirúa (VIIIème région, Chili): L’ethnicité comme ressource spatiale”. Mémoire de Maîtrese en Géographie. Paris: Université Paris III- Sorbonne Nouvelle, IHEAL, 2004.

Dehouve, Danielle. Ensayo de Geopolitica indígena. Los municipios tlapanecos. México: Centro de Investigaciones y Estudios Superiores en Antropología y Porrúa, 2001.

Delamaza, Gonzalo. Tan lejos tan cerca. Politicas públicas y sociedad civil en Chile. Santiago, Chile: LOM, 2005.

De la Peña, Guillermo. “Territorio y ciudadanía étnica en la nación globalizada”, Desacatos 1/1 (1999): 13-27.

Espinosa, María. "Descentralización, poderes locales indígenas y manejo de recursos naturales en el Ecuador”. En Willem Assies (Ed.), Gobiernos locales y reforma del Estado en América Latina. Zamora: Colegio de Michoacán (COLMICH), (2003): 189- 207.

Espinoza, Claudio. "Mapuches y poder local. Transformaciones en el escenario político de Tirúa (1992-2008), Chile”. Tesis de Doctorado en Antropología. México: Centro de Investigaciones y Estudios Superiores en Antropología, 2011.

Flores, Fabián y Robles, Claudia. "La unidad y la diversidad: Movilización política y demandas educacionales en el pueblo mapuche”, ISEES 2 (2007): 179214. Disponible en: http://www.isees.org/file.aspx?id=7525.

Foerster, Rolf y Lavanchy, Javier. "La problemática mapuche”, Análisis del año 1999, Departamento de Sociología, Universidad de Chile, Santiago, FACSO (1999): 65-102.

Foerster, Rolf y Vergara, Jorge. "Algunas transformaciones de la política mapuche en la década de los noventa", Anales de la Universidad de Chile 13 / 6 (2001): 2-23. Disponible en: http://www.anales.uchile.cl/index.php/ANUC/ article/viewFile/2528/2443.

Foerster, Rolf y Vergara, Jorge. "Permanencia y transformación del conflicto Estado-mapuches en Chile”, Revista Austral de Ciencias Sociales 6 (2002): $35-45$. 
Gelcich, Stefan, Edwards-Jones, Gareth, Kaiser, Michel y Castilla, Juan. "Comanagement Policy Can Reduce Resilience in Traditionally Managed Marine Ecosystems", Ecosystems 9 (2006): 951-966.

Gros, Christian. Politicas de la etnicidad: Identidad, Estado y modernidad. Bogotá: Instituto Colombiano de Antropología e Historia, 2003.

Harvey, Neil. "Gobernar en la diversidad: análisis comparativo". Gobernar (en) la diversidad: experiencias indígenas desde América Latina. Hacia la investigación de co-labor. En Xochitl Leyva, Araceli y Shannon Speed (Coords.), México, D.F: Centro de Investigaciones y Estudios Superiores en Antropología Social (CIESAS), Facultad Latinoamerica de Ciencias Sociales (FLACSO) Ecuador y Guatemala, (2008): 525- 541.

Hoffmann, Odile y Rodríguez, María Teresa. "Introducción”. Los retos de la diferencia. Los actores de la multiculturalidad entre México y Colombia. En Odile Hoffmann y María Teresa Rodríguez (Eds.), México: Centro de Estudios Mexicanos y Centroamericanos (CEMCA), Centro de Investgaciones y Estudios Superiores en Antropologia Social (CIESAS), Instituto Colombiano de Antropología e Historia (ICANH) e Institut de Recherche pour le Développment (IRD), (2007): 13-54.

Huenul, Susana. "Construcción sociopolítica de la 'Ley Lafkenche”, Ta in fijke xipa rakizuameluwün, Historia, colonialismo y resistencia desde el pais mapuche, VVAA. Temuco: Comunidad de Historia Mapuche, (2012): 215-239.

Iturralde, Diego. "Movimientos indígenas y contiendas electorales (Ecuador y Bolivia. Autonomías étnicas y Estados nacionales. En Miguel A. Bartolomé y Alicia Barabas (Coords.), México: Instituto Nacional de Antropología en Historia (INAH), (1998): 231-241.

Laurent, Virginie. Comunidades indígenas, espacios politicos y movilización electoral en Colombia, 1990-1998. Motivaciones, campos de acción e impactos. Bogotá: Instituto Francés de Estudios Andinos (IFEA) e Instituto Colombiano de Antropologia e Historia (ICANH), 2005.

Le Bot, Yvon. La Gran Revuelta Indigena. México: Universidad Iberoamericana Puebla y Océano, 2013. 
Mella, Magaly. "Movimiento mapuche en Chile: 1977-2000”. Tesis de Licenciatura en Antropología. Santiago, Chile: Universidad Academia de Humanismo Cristiano, 2001.

Ospina, Pablo. "Movimiento indígena ecuatoriano, gobierno territorial local y desarrollo económico: los casos del Gobierno Municipal de Cotacachi y el Gobierno Provincial de Cotopaxi" Las fisuras del poder. En Pablo Ospina (Comp.), Quito: Instituto de Estudios Ecuatorianos (IEE), (2006): 15118.

Pinto, Jorge. "El conflicto Estado-Pueblo Mapuche, 1900-1960", Universum 27/1 (2012):167-189.

Ramírez, Luis. "Movimientos indígenas y gobiernos locales en la región purépecha de Michoacán, México". Movimientos indigenas y gobiernos locales en América Latina. En Willem Assies y Hans Gundermann (Eds.), San Pedro de Atacama: Universidad Católica del Norte e Instituto de Investigaciones Arqueológicas y Museo (IIAM), (2007): 119-160.

Ramírez, Luis. Los retos de la gestión municipal de Zamora y Zacapu. Entre la ortodoxia partidista y la participación ciudadana. Zamora: El Colegio de Michoacán (COLMICH), 2009.

Restrepo, Eduardo. "Imaginando comunidad negra: Etnografía de la etnización de las poblaciones negras del Pacífico Sur colombiano". En Mauricio Pardo (Ed.), Acción colectiva, Estado y etnicidad en el Pacifico colombiano. Bogotá: Instituto Colombiano de Antropología e Historia (ICANH), (2001): 4170 .

Vergara, Jorge Iván, Gundermann, Hans y Foerster, Rodolfo. Estado, conflicto étnico y cultura. Estudio sobre pueblos sindigenas en Chile. Antofagasta: Instituto de Investigaciones Arqueológicas y Museo R.P. Gustavo Le Paige s.j. (QILLQA), Universidad Católica del Norte y Universidad de Antofagasta, 2013.

Zárate, Eduardo. Los señores de la utopía. Etnicidad politica en una comunidad purhépecha. Zamora: El Colegio de Michoacán (COLMICH), 1994. 


\section{Páginas visitadas:}

http://pegundugun.entodaspartes.net [Consultado el 03 de julio de 2010].

http://www.identidadlafkenche.cl/ [Consultado el 20 de diciembre de 2011].

http://www.pangea.org/asopxi/archivos_millarau.htm [Consultado el 17 de abril de 2009]. 